\title{
Comparative biodistribution of $12{ }^{111}$ In-labelled gastrin/CCK2 receptor-targeting peptides
}

\author{
Peter Laverman • Lieke Joosten • Annemarie Eek • Susan Roosenburg • \\ Petra Kolenc Peitl • Theodosia Maina • Helmut Mäcke • Luigi Aloj • \\ Elisabeth von Guggenberg • Jane K. Sosabowski • Marion de Jong • \\ Jean-Claude Reubi • Wim J. G. Oyen • Otto C. Boerman
}

Received: 2 December 2010 / Accepted: 15 March 2011 /Published online: 2 April 2011

(C) The Author(s) 2011. This article is published with open access at Springerlink.com

\begin{abstract}
Purpose Cholecystokinin 2 (CCK-2) receptor overexpression has been demonstrated in various tumours such as medullary thyroid carcinomas and small-cell lung cancers. Due to this high expression, CCK-2 receptors might be suitable targets for radionuclide imaging and/or radionuclide therapy. Several CCK-2 receptor-binding radiopeptides have been developed and some have been tested in patients. Here we aimed to compare the in vivo tumour targeting properties of $12{ }^{111} \mathrm{In}$ labelled 1,4,7,10-tetraazacyclododecane-1,4,7,10-tetraacetic acid (DOTA)-conjugated gastrin/CCK2 receptor-binding peptides.

Methods Two CCK8-based peptides and ten gastrin-based peptide analogues were tested. All peptides were conjugated with DOTA and labelled with ${ }^{111}$ In. Biodistribution studies were performed in mice with subcutaneous CCK2/
\end{abstract}

P. Laverman $(\bowtie) \cdot$ L. Joosten $\cdot$ A. Eek $\cdot$ S. Roosenburg $\cdot$

W. J. G. Oyen · O. C. Boerman

Department of Nuclear Medicine,

Radboud University Nijmegen Medical Centre,

$6500 \mathrm{HB}$, Nijmegen, The Netherlands

e-mail: p.laverman@nucmed.umcn.nl

\section{P. K. Peitl}

Department of Nuclear Medicine,

University Medical Centre Ljubljana,

Ljubljana, Slovenia

\section{T. Maina}

Molecular Radiopharmacy,

Institute of Radioisotopes-Radiodiagnostic Products,

National Center for Scientific Research Demokritos,

Athens, Greece

\section{H. Mäcke}

Department of Nuclear Medicine, University Hospital Freiburg,

Freiburg, Germany gastrin receptor-expressing tumours and with receptornegative tumours contralaterally. Biodistribution was studied by counting dissected tissues at 1 and $4 \mathrm{~h}$ after injection. Results Both the CCK analogues displayed relatively low tumour uptake (approximately $2.5 \% \mathrm{ID} / \mathrm{g}$ ) as compared to minigastrin analogues. Two linear minigastrin peptides (MG0 and sargastrin) displayed moderate tumour uptake at both 1 and $4 \mathrm{~h}$ after injection, but also very high kidney uptake (both higher than $48 \% \mathrm{ID} / \mathrm{g}$ ). The linear MG11, lacking the penta-Glu sequence, showed lower tumour uptake and also low kidney uptake. Varying the N-terminal Glu residues in the minigastrin analogues led to improved tumour targeting properties, with PP-F11 displaying the optimal biodistribution. Besides the monomeric linear peptides, a cyclized peptide and a divalent peptide were tested.

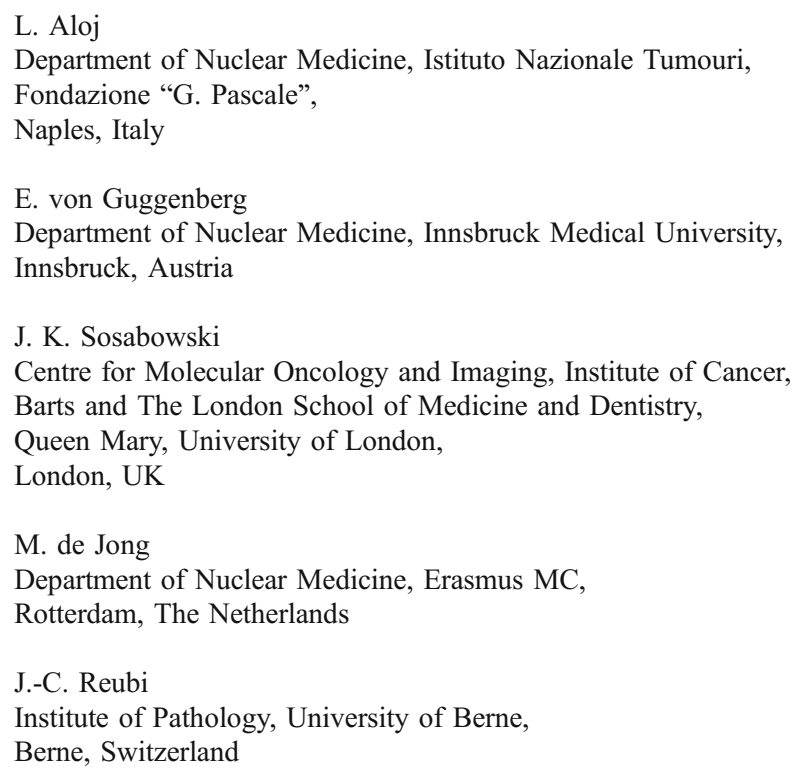


Conclusion Based on these studies, optimal peptides for peptide receptor radionuclide targeting of CCK2/gastrin receptor-expressing tumours were the linear minigastrin analogue with six D-Glu residues (PP-F11), the divalent analogue MGD5 and the cyclic peptide cyclo-MG1. These peptides combined high tumour uptake with low kidney retention, and may therefore be good candidates for future clinical studies.

Keywords Gastrin · Cholecystokinin · Tumour · DOTA

\section{Introduction}

Cholecystokinin 2 (CCK-2) receptor overexpression has been demonstrated in a high percentage of various tumours such as medullary thyroid carcinomas $(>90 \%)$ and smallcell lung cancer (89\%) [1]. Due to this high expression, CCK-2 receptors might be suitable targets for radionuclide imaging and/or radionuclide therapy.

The peptides of the gastrin and CCK family are characterized by an amidated $\mathrm{C}$-terminal receptor binding sequence Trp-Met-Asp-Phe- $\mathrm{NH}_{2}$. Gastrin peptides have a pentaglutamic acid sequence, which is absent in the CCK peptides. In addition, both groups of peptides differ by the location of their tyrosyl residue in relation to the receptor binding sequence. Peptides of the gastrin family have one amino acid (usually Gly), and peptides of the CCK family have two amino acids (Met-Gly or Thr-Gly) between this Tyr moiety and the receptor binding sequence. In CCK analogues, this Tyr residue plays a role in the receptor specificity. When this Tyr residue is sulphated, the peptides display high affinity for both the CCK1 and the CCK2 receptor ( $8 \mathrm{nM}$ and $3 \mathrm{nM}$, respectively). In contrast, the nonsulphated peptides show a 1,000-fold lower affinity for the CCK1 receptor than for the CCK2 receptor [2].

Aloj et al. [3] studied tumour targeting of glycine extended nonsulphated CCK8. As sulphation of the Tyr residue leads to enhanced tumour targeting [4], based on sulphated CCK $8, \operatorname{sCCK} 8\left[\mathrm{Phe}^{2}\left(\mathrm{p}-\mathrm{CH}_{2} \mathrm{SO}_{3} \mathrm{H}\right), \mathrm{HPG}^{3,6}\right]$ (SA106) has been developed. In this peptide two Met residues are replaced by homopropargyl glycine to prevent oxidation of these amino acids, which are required for receptor binding [5]. Whereas the CCK analogues generally display moderate tumour uptake and low kidney accumulation, the gastrin analogues show a much better tumour uptake, but this is accompanied by a high kidney uptake. When using these radiolabelled peptides for peptide receptor radionuclide therapy, the high kidney uptake is undesirable. This will lead to a high radiation dose to the kidneys, thus hampering radionuclide therapy.

Marsouvanidis et al. developed a DOTA-conjugated analogue of human gastrin-17, called sargastrin [6]. To optimize in vivo characteristics, Good et al. synthesized N- terminally truncated versions of the gastrin peptide. Minigastrin 0 (MG0) is a 12 amino acid peptide with a macrocyclic chelator coupled N-terminally via a D-Glu residue. In MG11, the pentaglutamic acid sequence has been deleted yielding an octapeptide with much lower kidney uptake [7] . Based on these data it was hypothesized that the negative charge of the pentaglutamic acid sequence is responsible for the high kidney retention. Therefore, in an attempt to decrease the kidney uptake, in PP-F10 the Glu residues were replaced by D-Gln residues. In addition, in PP-F11, the pentaglutamic acid sequence has been replaced by five D-glutamic acid residues yielding a hexa D-Glu sequence. Furthermore, PP-F16 was synthesized with three D-Gln and three D-Glu residues alternately. Finally, PP-F6 was synthesized with only three D-Gln residues. Based on MG11, the peptide APH070 has been synthesized [8]. This peptide has two additional histidyl residues N-terminally, yielding a better tumour-to-kidney ratio than the parent MG11. In an attempt to increase receptor affinity and tumour uptake, Sosabowski et al. [9] synthesized a DOTAconjugated divalent minigastrin (MGD5) that demonstrates improved tumour targeting compared to the monomeric form of the peptide (APH070). In another approach von Guggenberg et al. used a cyclic form of minigastrin (cycloMG1) and labelled it with ${ }^{99 \mathrm{~m}} \mathrm{Tc}$ for imaging of CCK2/ gastrin receptor-expressing tumours [10].

In vitro and in vivo characteristics of some of these peptides have been described before. The present study, however, is the first side-by-side comparison of their biodistribution in tumour-bearing mice.

\section{Materials and methods}

Peptides

All peptides were synthesized using standard Fmoc-based solid-phase peptide synthesis and conjugated with 1,4,7,10tetraazacyclododecane-1,4,7,10-tetraacetic acid (DOTA), using one of the carboxylic groups of DOTA. No linkers between DOTA and peptide were used. All peptide structures were confirmed by mass spectrometry and NMR. Peptides were dissolved in appropriate buffers. Table 1 lists the names, amino acid sequences and molecular weights of the peptides. All buffers used for the radiolabelling procedures were metal-free. Metal-free buffers were obtained by treatment with Chelex100 resin (BioRad, Hercules, CA) and subsequent filtration through a $0.22-\mu \mathrm{m}$ filter.

Radiolabelling

DOTA-conjugated peptides were radiolabelled with ${ }^{111}$ In by incubation with ${ }^{111} \mathrm{InCl}_{3}$ (Covidien, Petten, The Netherlands) 
Table 1 Amino acid sequences of the peptides

\begin{tabular}{|c|c|c|c|}
\hline Name & Sequence & MW (g/mol) & Reference \\
\hline G-CCK8 & DOTA-Gly-Asp-Tyr-Met-Gly-Trp-Met-Asp-Phe- $\mathrm{NH}_{2}$ & $1,507.0$ & [3] \\
\hline SA106 & DOTA-DAsp-Phe(p- $\left.\mathrm{CH}_{2} \mathrm{SO}_{3} \mathrm{H}\right)$-HPG-Gly-Trp-HPG-Asp-Phe- $\mathrm{NH}_{2}$ & $1,482.6$ & {$[5]$} \\
\hline MG0 & DOTA-DGlu-Glu-Glu-Glu-Glu-Glu-Ala-Tyr-Gly-Trp-Met-Asp-Phe-NH ${ }_{2}$ & $2,037.0$ & [7] \\
\hline Sargastrin & DOTA-Gln-Gly-Pro-Trp-Leu-Glu-Glu-Glu-Glu-Glu-Ala-Tyr-Gly-Trp-Nle-Asp-Phe-NH ${ }_{2}$ & $2,483.6$ & - \\
\hline MG11 & DOTA-DGlu-Ala-Tyr-Gly-Trp-Met-Asp-Phe- $\mathrm{NH}_{2}$ & $1,531.0$ & [7] \\
\hline APH070 & DOTA-His-His-Glu-Ala-Tyr-Gly-Trp-Met-Asp-Phe- $\mathrm{NH}_{2}$ & $1,677.8$ & {$[8]$} \\
\hline PP-F10 & DOTA-DGln-DGln-DGln-DGln-DGln-DGln-Ala-Tyr-Gly-Trp-Met-Asp-Phe-NH 2 & $2,042.9$ & - \\
\hline PP-F6 & DOTA-DGln-DGln-DGln-Ala-Tyr-Gly-Trp-Met-Asp-Phe-NH 2 & $1,658.7$ & - \\
\hline PP-F16 & DOTA-DGln-DGlu-DGln-DGlu-DGln-DGlu-Ala-Tyr-Gly-Trp-Met-Asp-Phe-NH ${ }_{2}$ & $2,045.9$ & - \\
\hline PP-F11 & DOTA-DGlu-DGlu-DGlu-DGlu-DGlu-DGlu-Ala-Tyr-Gly-Trp-Met-Asp-Phe-NH ${ }_{2}$ & $2,048.8$ & - \\
\hline Cyclo-MG1 & DOTA-DGlu-(Ala-Tyr)-DLys-Trp-Met-Asp-Phe- $\mathrm{NH}_{2}$ (cyclo DGlu-DLys) & $1,455.7$ & {$[10]$} \\
\hline MGD5 & DOTA-Gly-Ser-Cys-(Glu-Ala-Tyr-Gly-Trp-Nle-Asp-Phe-NH $)_{2}$ & $2,782.9$ & [9] \\
\hline
\end{tabular}

$H P G$ homopropargyl glycine

in $0.25 \mathrm{M}$ ammonium acetate buffer, $\mathrm{pH}$ 5.0. To prevent oxidation of the peptides during radiolabelling, $100 \mu \mathrm{g}$ $(10 \mu \mathrm{l})$ selenomethionine was added. The labelling mixture was incubated for $30 \mathrm{~min}$ at $95^{\circ} \mathrm{C}$. After incubation, $50 \mathrm{mM}$ EDTA was added to a final concentration of $5 \mathrm{mM}$. Radiochemical purity and the presence of oxidized peptide was checked on an HPLC system (1200 series LC system; Agilent Technologies, Palo Alto, CA) equipped with an Alltima RP-C18 column (5 $\mu \mathrm{m}, 4.6 \times 250 \mathrm{~mm}$; Alltech, Deerfield, IL) and an in-line NaI radiodetector (Raytest, Straubenhardt, Germany). A gradient from $0.1 \%$ trifluoroacetic acid in water to $0.1 \%$ trifluoroacetic acid in acetonitrile was used. The specific activity of all peptides was $11 \mathrm{GBq} / \mu \mathrm{mol}$ and radiochemical purity was always higher than $95 \%$.

\section{Cell culture}

Two transfected human epidermoid carcinoma cell lines (A431) were used. Stably transfected cells were constructed as described previously [3]. Cell lines were stably transfected with cDNA encoding for CCK2R or with empty vector ('mock-transfected'). Cells were cultured in Dulbecco's modified Eagle's medium (DMEM; Gibco Life Technologies, Gaithersburg, MD) supplemented with 4,500 mg/l Dglucose, $10 \%(\mathrm{v} / \mathrm{v})$ fetal calf serum, $2 \mathrm{mmol} / 1$ glutamine and $250 \mu \mathrm{g} / \mathrm{ml} \mathrm{G} 418$. Cells were cultured at $37^{\circ} \mathrm{C}$ in a humidified atmosphere containing $5 \% \mathrm{CO}_{2}$.

\section{Biodistribution studies}

Tumour targeting of the ${ }^{111}$ In-labelled peptides was studied in female athymic BALB/c mice with subcutaneous tumours induced by inoculation of CCK2 receptor-transfected and mock-transfected A431 cells. Mice were inoculated with $2 \times$
$10^{6}$ A431-CCK2R cells $(0.2 \mathrm{ml})$ in the left flank and with A431 mock-transfected cells in the right flank. After approximately 10 days, when the tumours had reached a weight of approximately $0.1-0.2 \mathrm{~g}$, the mice were randomly divided into groups of five mice. The mice were injected intravenously with $370 \mathrm{kBq}(0.03 \mathrm{nmol})$ of ${ }^{111}$ In-labelled peptide via the lateral tail vein. In addition, one group of mice was injected with a 1,000-fold molar excess of the same unlabelled peptide to determine the non-CCK2Rmediated uptake in CCK2R-expressing tissues. Mice were killed by $\mathrm{CO}_{2}$ asphyxiation at 1 and $4 \mathrm{~h}$ post-injection (p.i.). The group injected with an excess of unlabelled peptide was dissected at $4 \mathrm{~h}$ p.i. A blood sample was drawn and organs of interest and the tumour were dissected, weighed and counted in a gamma counter. The animal experiments were approved by the local animal welfare committee and performed according to national regulations.

\section{Statistical analysis}

All mean values are given \pm standard deviation (SD). Statistical analysis was performed using a Welch's corrected unpaired Student's $t$-test or one-way analysis of variance using StatMate software (version 2.00, GraphPad Software). The level of significance was set at $P<0.05$.

\section{Results}

Two CCK8 analogues were evaluated. DOTA-conjugated nonsulphated CCK8 (G-CCK8) displayed moderate tumour uptake $(2.44 \pm 1.45 \% \mathrm{ID} / \mathrm{g}$ at $4 \mathrm{~h}$ p.i.) with low uptake in nontarget tissues including the kidneys (Fig. 1). A stabilized form of sulphated CCK8 ( $\mathrm{sCCK} 8\left[\mathrm{Phe}^{2}(\mathrm{p}-\right.$ $\left.\mathrm{CH}_{2} \mathrm{SO}_{3} \mathrm{H}\right), \mathrm{HPG}^{3,6}$, SA106) showed moderate tumour 
localization $(2.65 \pm 0.59 \% \mathrm{ID} / \mathrm{g}$ at $4 \mathrm{~h}$ p.i.) and specific accumulation in the pancreas $(1.82 \pm 0.27 \% \mathrm{ID} / \mathrm{g}$ at $4 \mathrm{~h}$ p.i.). Uptake in all other organs was low.

Ten gastrin-based analogues were included in these studies. Overall, these peptides had a higher uptake in CCK2R-expressing tumours than the CCK analogues. The largest peptide, sargastrin, displayed a high tumour uptake $(11.8 \pm 3.1 \% \mathrm{ID} / \mathrm{g}$ and $9.83 \pm 4.3 \% \mathrm{ID} / \mathrm{g}, 1$ and $4 \mathrm{~h}$ p.i., respectively), but also showed very high uptake in the kidneys

\section{G-CCK8}

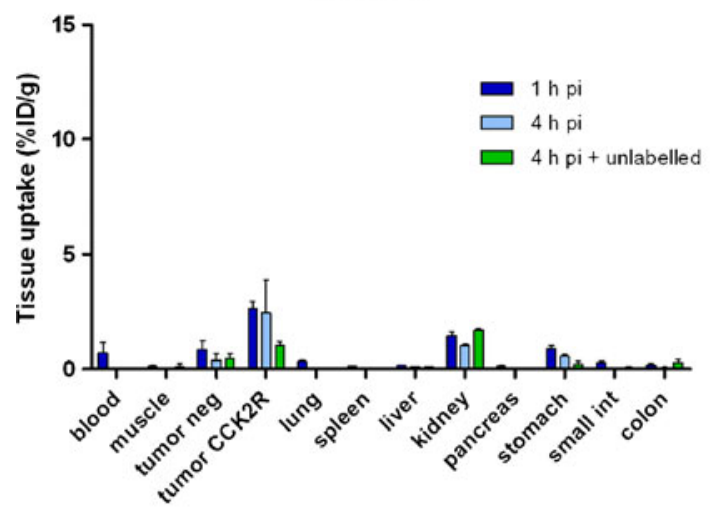

MG0

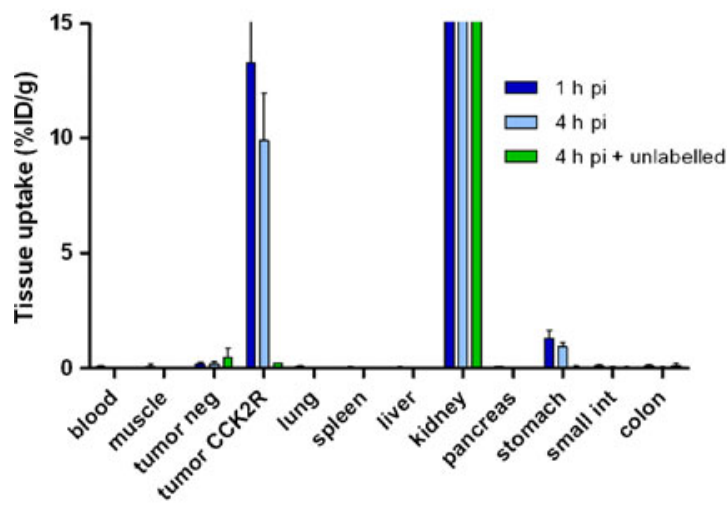

MG11

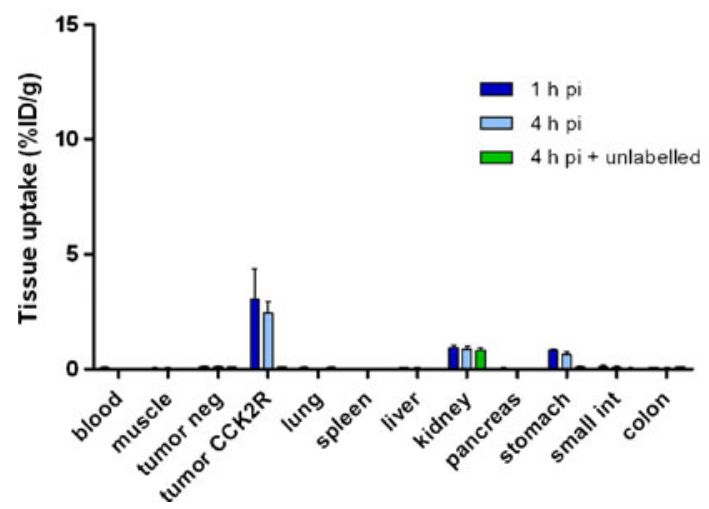

Fig. 1 Tissue distribution of ${ }^{111}$ In-labelled peptides in mice $(n=5 /$ group) with subcutaneous A431-CCK2R and A431 negative control tumours at 1 and $4 \mathrm{~h}$ p.i. Uptake of radioactivity is expressed as
(57.2 \pm 3.4 and $60.3 \pm 4.8 \% \mathrm{ID} / \mathrm{g}, 1$ and $4 \mathrm{~h}$ p.i., respectively). The N-terminally truncated gastrin peptide MG0 also showed high tumour uptake $(13.3 \pm 4.9 \% \mathrm{ID} / \mathrm{g}$ and $9.9 \pm 2.0 \% \mathrm{ID} / \mathrm{g}, 1$ and $4 \mathrm{~h}$ p.i., respectively), but the retention in the kidneys showed a similarly high level as that of sargastrin (Fig. 1). MG11 (lacking the penta-Glu sequence) displayed a strongly reduced kidney uptake $(0.91 \pm 0.14 \% \mathrm{ID} / \mathrm{g}$ at $1 \mathrm{~h}$ p.i. $)$, but also tumour uptake was reduced to only one-third of that of sargastrin and MG0 (3.04 $\pm 1.30 \% \mathrm{ID} / \mathrm{g}$ at $1 \mathrm{~h}$ p.i.). In APH070, two His

\section{SA106}

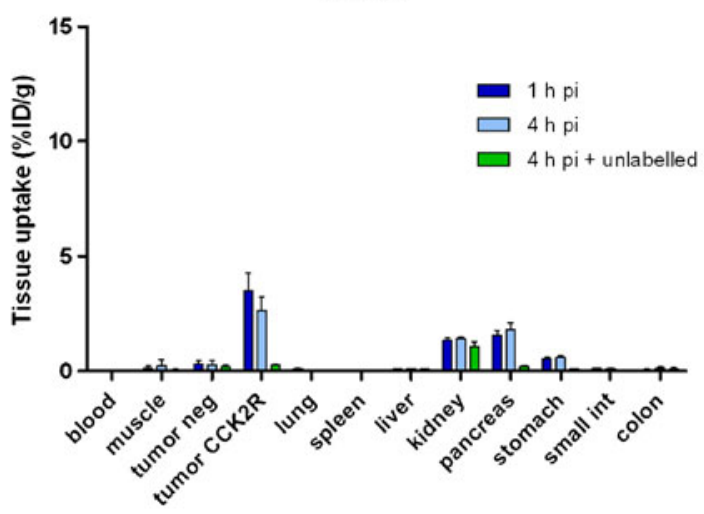

Sargastrin

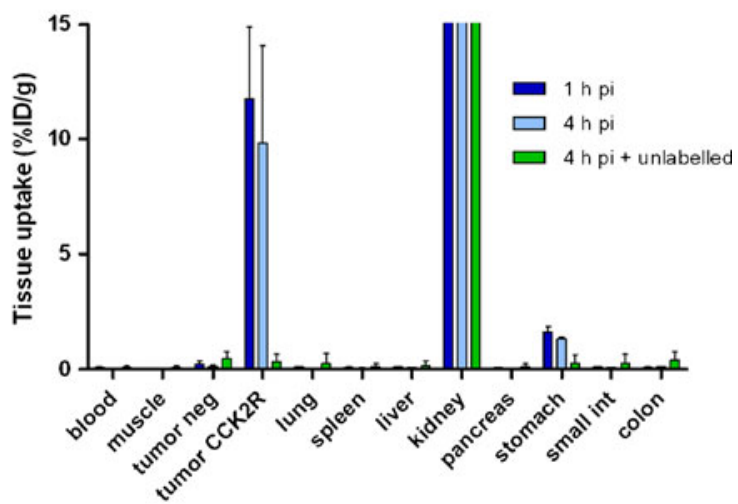

APH070

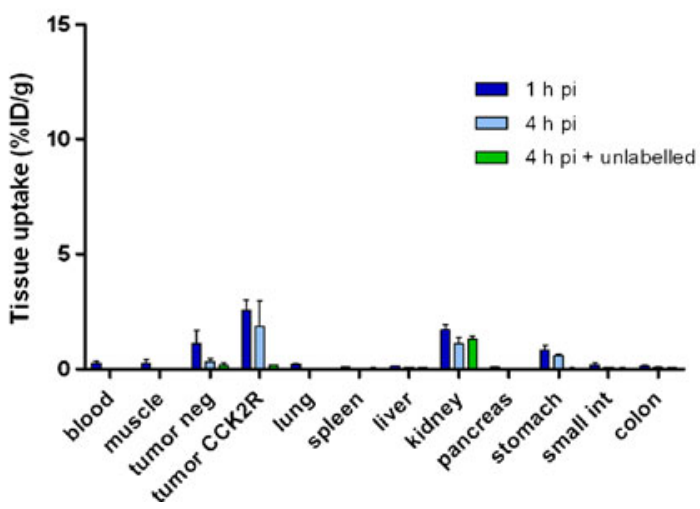

percentage of the injected dose per gram $(\% \mathrm{ID} / \mathrm{g})$. Kidney uptake of MG0 and sargastrin (centre) is truncated to allow comparison with other peptides. Error bars represent standard deviation 
PP-F10

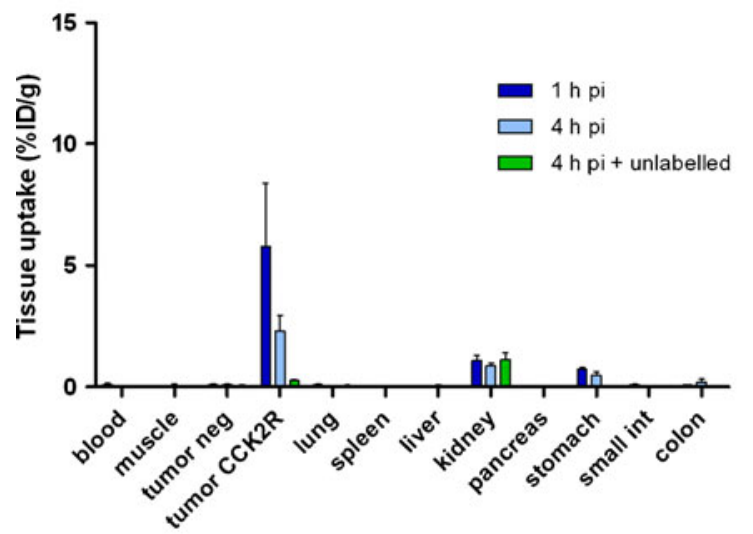

PP-F16

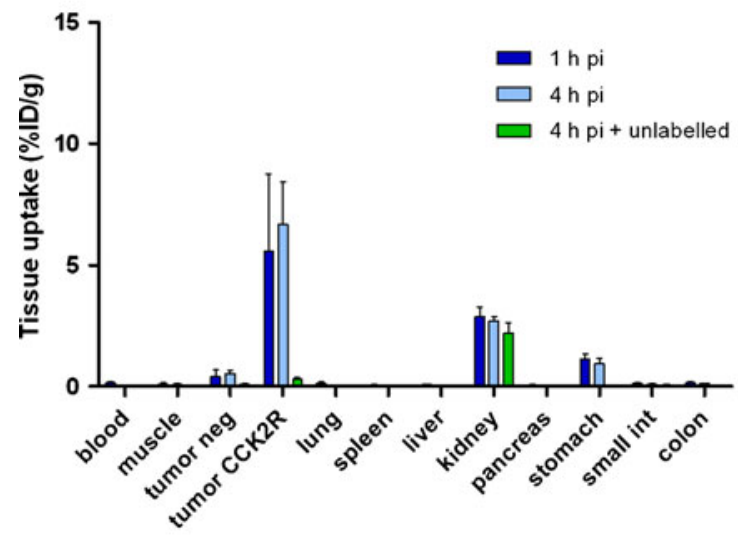

CycloMG1

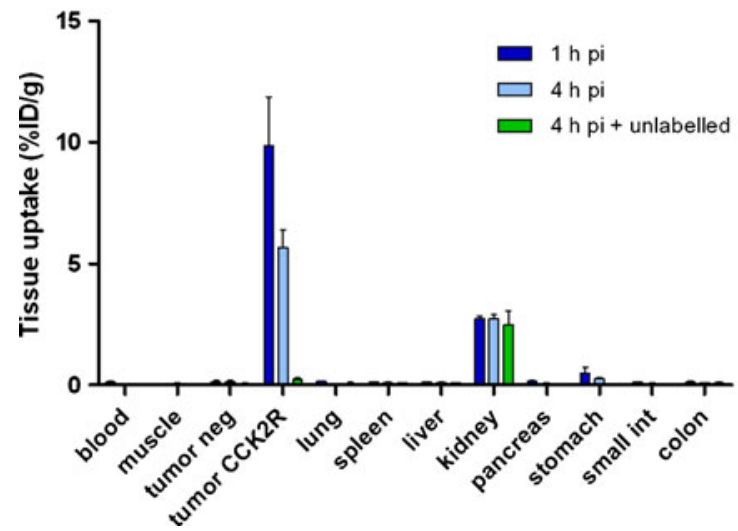

Fig. 1 (continued)

residues were attached N-terminally to the MG0 sequence [8]. Although displaying low kidney uptake, tumour uptake was also moderate and comparable to that of MG11.

A series of MG0 analogues were synthesized with varying sequences of N-terminal amino acids. Peptide PPF6 consists of the seven amino acid C-terminal sequence of gastrin with three D-Gln residues added $\mathrm{N}$-terminally and PP-F10 was elongated with six D-Gln residues. Both
PP-F6

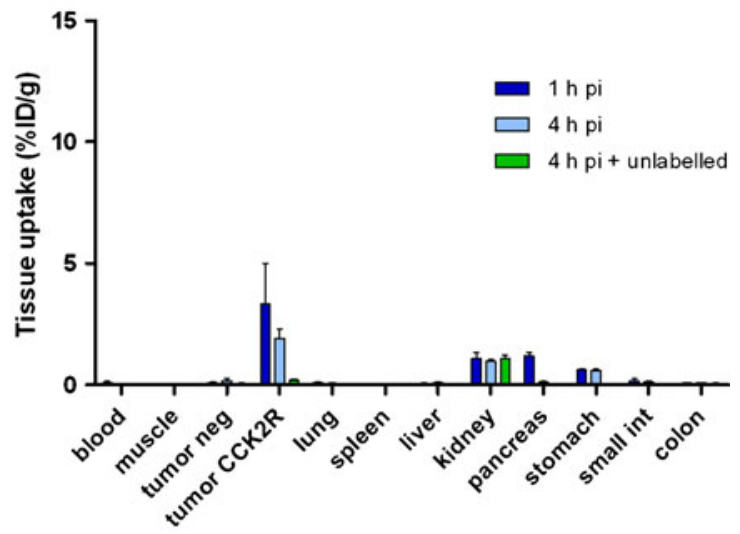

PP-F11

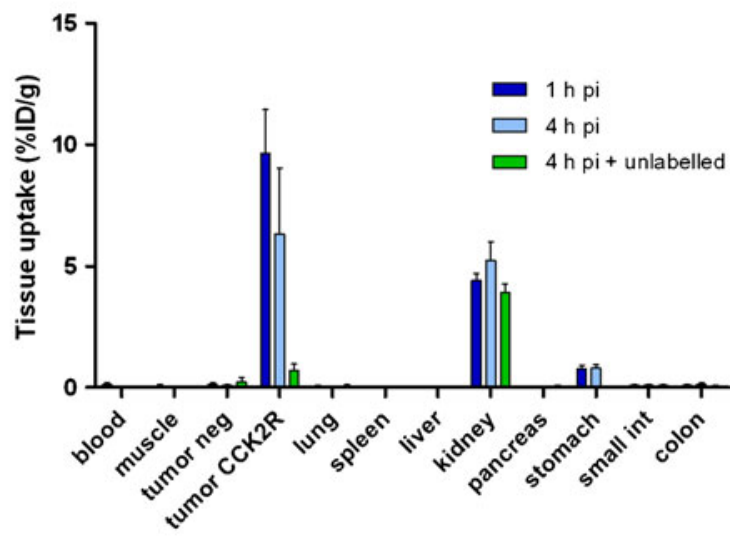

MGD5

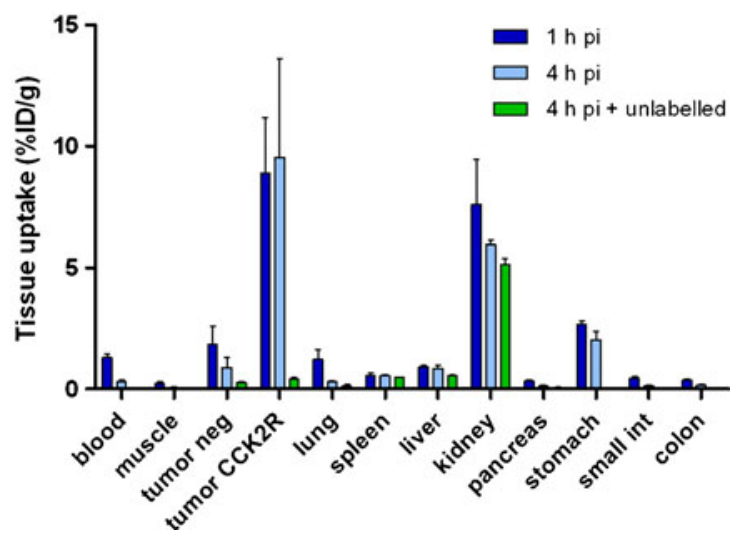

peptides showed very low kidney uptake (both $\leq 1 \% \mathrm{ID} / \mathrm{g}$ at $1 \mathrm{~h}$ p.i.), but only moderate tumour uptake $(1.93 \pm 0.37$ and $2.31 \pm 0.64 \% \mathrm{ID} / \mathrm{g}$, PP-F6 and PP-F10, respectively, $4 \mathrm{~h}$ p.i.). Substituting the six N-terminal residues by D-Glu resulted in a favourable biodistribution with high tumour uptake and retention $(9.66 \pm 1.78$ and $6.30 \pm 2.75 \% \mathrm{ID} / \mathrm{g}, 1$ and $4 \mathrm{~h}$ p.i.) accompanied by low kidney retention. The sequence of this peptide is identical to that of MG0, but the 
N-terminal L-Glu residues have been replaced by their Disomers. While maintaining tumour accumulation, kidney retention was only one-tenth that of MG0, resulting in a high tumour-to-blood ratio $(448 \pm 210)$ and tumour-tokidney ratio $(1.2 \pm 0.5)$ at $4 \mathrm{~h}$ p.i. (Fig. 2). The analogue with the hexaamino acid sequence with alternating D-Glu and D-Gln residues (PP-F16) displayed only moderate tumour uptake $(5.56 \pm 3.20 \% \mathrm{ID} / \mathrm{g}$ at $1 \mathrm{~h}$ p.i.).

Since multimerization has been shown to be an effective approach to increasing stability and affinity [11], the minigastrin sequence was dimerized using Cys, and in addition the Met residue was replaced by Nle to prevent oxidation [9]. These changes (MGD5) led to improved tumour accumulation but also to higher uptake in other organs, including the kidney.
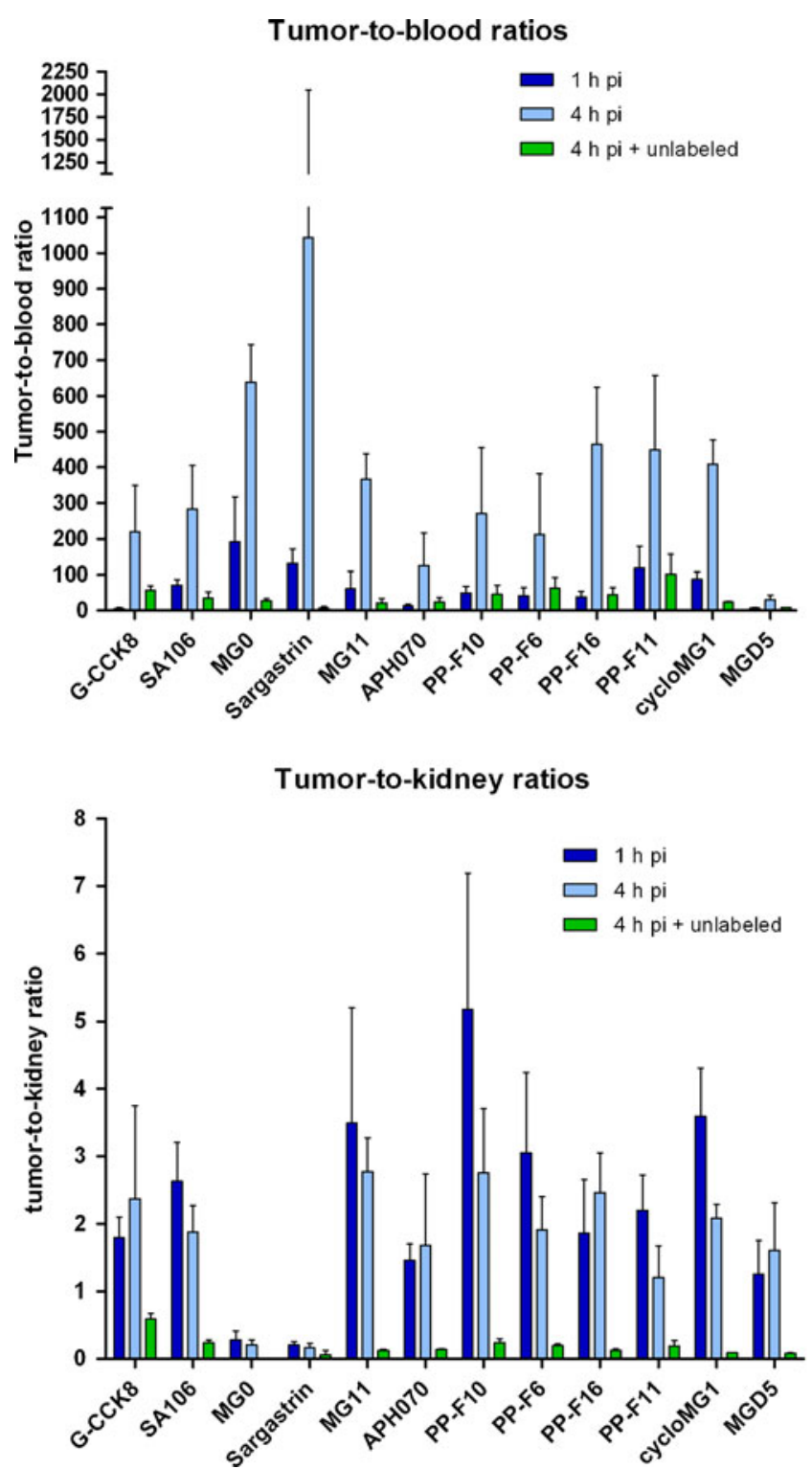

Fig. 2 Tumour-to-blood and tumour-to-kidney ratios of ${ }^{111}$ In-labelled peptides in A431-CCK2R tumours in mice ( $n=5 /$ group) at 1 and $4 \mathrm{~h} \mathrm{p.i}$
In an attempt to improve the in vivo characteristics, a cyclized analogue based on MG11, cyclo-MG1, has been synthesized and tested. Indeed, tumour targeting of cycloMG1 was high $(9.88 \pm 1.99 \% \mathrm{ID} / \mathrm{g}$ at $1 \mathrm{~h}$ p.i. $)$ and kidney accumulation was low $(2.75 \pm 0.11 \% \mathrm{ID} / \mathrm{g}$ at $1 \mathrm{~h} \mathrm{p}$.i.). Tumour uptake at $4 \mathrm{~h}$ p.i. suggested that tumour retention of this peptide was impaired since uptake at $4 \mathrm{~h}$ p.i. was more than $40 \%$ lower $(5.76 \pm 0.71 \% \mathrm{ID} / \mathrm{g})$ than at $1 \mathrm{~h}$ p.i. $(p=0.0067)$.

\section{Discussion}

During the past decade, a wide series of $\mathrm{CCK} /$ gastrin analogues have been produced and tested in vitro and in vivo. Here we compared the biodistribution of 12 CCK2/ gastrin receptor targeting peptides in mice with CCK2Rexpressing tumours. Ten of these peptides were gastrin analogues, and two peptides were CCK 8 derivatives. The CCK8 analogues showed lower tumour uptake accompanied by a low kidney retention. The sulphated peptide sCCK $8\left[\mathrm{Phe}^{2}\left(\mathrm{p}-\mathrm{CH}_{2} \mathrm{SO}_{3} \mathrm{H}\right), \mathrm{HPG}^{3,6}\right]$ (SA106) also showed affinity for the CCK1 receptor, resulting in specific accumulation in murine pancreas [4]. Specific uptake in the murine pancreas was not observed for the DOTA-CCK8 peptide (G-CCK8).

From the gastrin analogues, ${ }^{111}$ In-labelled MG0 and ${ }^{111}$ In-labelled sargastrin showed the highest kidney accumulation. This uptake was blocked by the coinjection of agents such as albumin fragments or gelatin-based plasma expanders [12]. In addition, Béhé et al. showed efficient blocking of the kidney uptake of ${ }^{111} \mathrm{In}$-MG0 by using polyGlu chains of various lengths [13]. In particular, oligo-Glu chains of more than five amino acids showed effective reduction in kidney accumulation. These data suggest that the high kidney retention is a result of the presence of five Glu residues. Indeed, reducing the number of Glu residues in MG0 resulted in a strong reduction of kidney uptake (MG11), but led to reduced tumour localization of only one-third of the uptake of MG0. It has been reported that MG11 is unstable in serum [7], indicating that the pentaGlu sequence may be responsible for in vivo stability and kidney uptake. To diminish kidney retention of the gastrin analogues, four peptides were developed with various $\mathrm{N}$ terminal sequences consisting of D-Glu and/or D-Gln residues. Except for these residues, peptide sequences were similar to those of MG0. Remarkably, replacing the five LGlu residues of MG0 by five D-Glu, the new analogue PPF11 showed markedly reduced kidney retention $(90 \%$ reduced) as compared to that of MG0, while maintaining high tumour uptake. Replacement by six D-Gln residues PP-F10 even further reduced kidney uptake, at the cost of uptake in the tumour. Tumour uptake was further reduced when using only three D-Gln residues. 
To further investigate the potential of a shortened gastrin analogue, Mather et al. screened a series of peptides [8] of which the peptide with two N-terminal His residues was selected for further studies. This peptide, APH070, combined improved stability with moderate tumour uptake, and although kidney uptake was very low, tumour-to-kidney ratios were lower as compared to several other gastrin analogues (Fig. 2).

The divalent MGD5 displayed good tumour uptake and retention, but showed high background levels in all organs. Blood levels at $1 \mathrm{~h}$ p.i. were generally tenfold higher than those of the other peptides investigated. These high background levels, most likely caused by the relatively high blood levels, are in disagreement with previous data [9] where background levels were three- to fivefold lower. This could be due to the fact that the present study was carried out in $\mathrm{BALB} / \mathrm{c}$ nude mice, while the peptide was previously tested in CD1 (SCID) mice.

Previously, von Guggenberg et al. reported on the development of two ${ }^{99 \mathrm{~m}} \mathrm{Tc}$-labelled cyclic minigastrin derivatives [10]. Based on HYNIC-cyclo-MG1, the DOTAconjugated form of this peptide was tested. This peptide combined high tumour accumulation with relatively low kidney retention, resulting in high tumour-to-blood ratios and good tumour-to-kidney ratios. Uptake in all other organs, including the stomach, was the lowest of all peptides studied. Whereas the ${ }^{99 \mathrm{~m}} \mathrm{Tc}$ compound showed good tumour retention at 1 and $4 \mathrm{~h}$ p.i. [10], the ${ }^{111}$ In-labelled DOTA cyclo-MG1 showed a more than $40 \%$ decrease in tumour retention between 1 and 4 h p.i.. Except for cyclo-MG1 and PP-F10, all other peptides showed good tumour retention of the radioactivity. The methods discussed above aimed to improve stability and affinity of the peptides. As described in another paper (Aloj et al., this issue), the affinity of all these 12 peptides was in the same low nanomolar range.

In summary, the highest tumour uptake was obtained with cyclo-MG1 $(9.2 \pm 1.0 \% \mathrm{ID} / \mathrm{g})$, PP-F11 $(9.7 \pm 1.8 \% \mathrm{ID} / \mathrm{g})$, MGD5 $(8.9 \pm 2.3 \% \mathrm{ID} / \mathrm{g})$, sargastrin $(11.8 \pm 3.1 \% \mathrm{ID} / \mathrm{g})$ and MG0 $(13.3 \pm 4.9 \% \mathrm{ID} / \mathrm{g})$. Of these compounds, sargastrin and MG0 suffered from high kidney uptake. Tumour retention of the cyclic peptide was lower than that of the other peptides. Tumour retention of the divalent peptide was stable between 1 and $4 \mathrm{~h}$ p.i.. In general, tumour-toblood and tumour-to-kidney ratios of the CCK analogues were lower than those of the gastrin analogues.

\section{Conclusion}

Based on these studies, optimal peptides for peptide receptor radionuclide targeting of $\mathrm{CCK} 2 /$ gastrin receptor-expressing tumours were the linear minigastrin analogue with six D-Glu residues (PP-F11), the divalent analogue MGD5 and the cyclic peptide cyclo-MG1. These peptides combined high tumour uptake with low kidney retention, and may therefore be good candidates for future clinical studies.

Acknowledgments This work was part of COST Action BM0607 within Framework 7 of the European Union.

Conflicts of interest None.

Open Access This article is distributed under the terms of the Creative Commons Attribution Noncommercial License which permits any noncommercial use, distribution, and reproduction in any medium, provided the original author(s) and source are credited.

\section{References}

1. Reubi JC, Schaer JC, Waser B. Cholecystokinin(CCK)-A and CCK-B/gastrin receptors in human tumors. Cancer Res. 1997;57 (7):1377-86.

2. Smeets RL, Fouraux MA, van Emst-de Vries SE, De Pont JJ, Willems PH. Protein kinase C-mediated inhibition of transmembrane signalling through $\mathrm{CCK}(\mathrm{A})$ and $\mathrm{CCK}(\mathrm{B})$ receptors. $\mathrm{Br} \mathrm{J}$ Pharmacol. 1998;123(6):1189-97.

3. Aloj L, Caraco C, Panico M, Zannetti A, Del Vecchio S, Tesauro D, et al. In vitro and in vivo evaluation of In-111-DTPAGlu-G-CCK8 for cholecystokinin-B receptor imaging. J Nucl Med. 2004;45(3):485-94.

4. Laverman P, Behe M, Oyen WJ, Willems PH, Corstens FH, Behr TM, et al. Two technetium-99m-labeled cholecystokinin8 (CCK8) peptides for scintigraphic imaging of CCK receptors. Bioconjug Chem. 2004;15(3):561-8.

5. Roosenburg S, Laverman P, Joosten L, Eek A, Oyen WJ, De JM, et al. Stabilized $111 \mathrm{In}$-labeled sCCK8 analogues for targeting CCK2-receptor positive tumors: synthesis and evaluation. Bioconjug Chem. 2010;21(4):663-70.

6. Marsouvanidis PJ, Tatsi A, Nock BA, Krenning EP, Maina T, de Jong M. [111In]Sargastrin, a Gastrin I-based radioligand targeting CCK2-R-positive tumors in vivo (abstract). Eur J Nucl Med Mol Imaging. 2009;36 Suppl 2:S259.

7. Good S, Walter MA, Waser B, Wang X, Muller-Brand J, Behe MP, et al. Macrocyclic chelator-coupled gastrin-based radiopharmaceuticals for targeting of gastrin receptor-expressing tumours. Eur J Nucl Med Mol Imaging. 2008;35(10):1868-77.

8. Mather SJ, McKenzie AJ, Sosabowski JK, Morris TM, Ellison D, Watson SA. Selection of radiolabeled gastrin analogs for peptide receptor-targeted radionuclide therapy. J Nucl Med. 2007;48(4):615-22.

9. Sosabowski JK, Matzow T, Foster JM, Finucane C, Ellison D, Watson SA, et al. Targeting of CCK-2 receptor-expressing tumors using a radiolabeled divalent gastrin peptide. J Nucl Med. 2009;50 (12):2082-9.

10. von Guggenberg E, Sallegger W, Helbok A, Ocak M, King R, Mather SJ, et al. Cyclic minigastrin analogues for gastrin receptor scintigraphy with technetium-99m: preclinical evaluation. J Med Chem. 2009;52(15):4786-93.

11. Dijkgraaf I, Kruijtzer JA, Liu S, Soede AC, Oyen WJ, Corstens $\mathrm{FH}$, et al. Improved targeting of the alpha(v)beta(3) integrin by multimerisation of RGD peptides. Eur J Nucl Med Mol Imaging. 2007;34(2):267-73.

12. Vegt E, Eek A, Oyen WJ, De JM, Gotthardt M, Boerman OC. Albumin-derived peptides efficiently reduce renal uptake of radiolabelled peptides. Eur J Nucl Med Mol Imaging. 2010;37(2):226-34.

13. Béhé M, Kluge G, Becker W, Gotthardt M, Behr TM. Use of polyglutamic acids to reduce uptake of radiometal-labeled minigastrin in the kidneys. J Nucl Med. 2005;46(6):1012-5. 